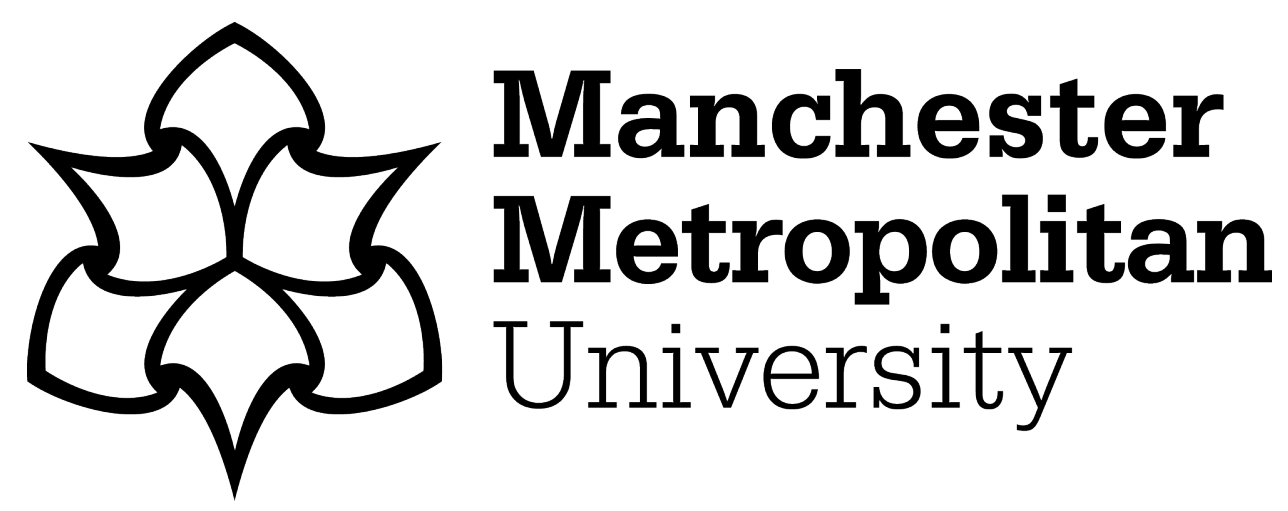

Stephens, G, O Neill, S, Clifford, C, Cuff, A, Forte, F, Hawthorn, C and Littlewood, C ORCID logoORCID: https://orcid.org/0000-0002-7703-727X (2019) Greater trochanteric pain syndrome in the UK National Health Service: a multicentre service evaluation. Musculoskeletal Care, 17 (4). pp. 390-398. ISSN 1478-2189

Downloaded from: https://e-space.mmu.ac.uk/625250/

Version: Accepted Version

Publisher: Wiley

DOI: https://doi.org/10.1002/msc.1419

Please cite the published version 


\section{Greater Trochanteric Pain Syndrome in the UK National Health Service: A multi-centre service evaluation}

Gareth Stephens ${ }^{1}$, Seth $\mathrm{O}^{\prime}$ Neill$^{2}$, Chris Clifford ${ }^{3}$, Andrew Cuff ${ }^{4}$, Felipe Forte ${ }^{5}$, Catrin Hawthorn ${ }^{6}$, Chris Littlewood ${ }^{7}$.

\footnotetext{
${ }^{1}$ The Royal Orthopaedic Hospital, Birmingham, UK.

${ }^{2}$ University of Leicester, East Midlands, UK.

${ }^{3}$ Gartnavel General Hospital, Glasgow, UK

${ }^{4}$ Wakefield Musculoskeletal Service, Trinity Medical Centre, Wakefield, UK.

${ }^{5}$ Sandwell and West Birmingham NHS Hospitals, UK.

${ }^{6}$ Glangwili Hospital, Carmarthen, UK

${ }^{7}$ Primary Care Centre versus Arthritis, Research Institute for Primary Care and Health Sciences, Keele University, Staffordshire, UK. c.littlewood@keele.ac.uk
}

${ }^{1}$ The Royal Orthopaedic Hospital NHS Trust, Physiotherapy Department, The Woodlands, Bristol Road South, Birmingham, B31 2AP.Tel.01216854120.Email. Gareth.stephens@nhs.net 


\section{INTRODUCTION}

Greater Trochanteric Pain syndrome (GTPS) is a debilitating condition causing lateral hip pain (Grimaldi \& Fearon, 2015). It affects up to $23.5 \%$ of women and $8 \%$ of men between $50-75$ years old (Segal et al., 2007). Existing data suggests that patients with GTPS report difficulty sleeping; and moderate to severe pain and disability, and comparable quality of life to people with advanced osteoarthritis of the hip (Fearon et al., 2013; Fearon et al., 2014). Originally considered an inflammatory condition of the trochanteric bursa; recent imaging, surgical and histology studies have suggested it to be, most commonly, a condition associated with tendinopathy of the gluteus medius and minimus tendons at the site of their insertion onto the greater tuberosity of the femur (Fearon et al., 2010; Long, Surrey \& Nazarian, 2013).

A recent randomised controlled trial (LEAP trial) reported $78.5 \%$ success rates on the global rating of change scale with education and exercise interventions for patients with GTPS (Mellor et al., 2018). These outcomes were superior to cortico-steroid injection (58.3\%) and wait and see (51.9\%) approaches at 12-months post intervention (Mellor et al., 2018). However, the patients recruited to this study were community dwellers and not patients seeking healthcare interventions. Patients were also excluded if they had advanced osteoarthritis of the hip (>2 Kellgren Lawrence scale) or knee, low back pain $(>2 / 10)$, systemic inflammatory diseases, or systemic diseases affecting the muscular or nervous system (Mellor et al, 2016). Current data suggests that patients with GTPS are often overweight, and complain of low back pain, osteoarthritis of the spine or ipsilateral hip or knee (Segal et al., 2007). GTPS is more common in post-menopausal women, and has also been shown to be highly prevalent in patients awaiting renal transplant (Demant et al., 2007; Lievense et al., 2015). The extent to which co-morbidities are present, and the impact of them in patients with GTPS is unknown, yet cardiovascular, hormonal and endocrine disorders are known risk factors for developing other lower limb tendinopathies (Abate, Schiavone, Salini \& Andia, 2013). Age, gender, family support, severity of symptoms, greater healthcare needs due to chronic conditions, and beliefs about disease and ability of healthcare to change it, are all factors which 
influence healthcare seeking behaviour (Cornally \& McCarthy, 2011; Thompson et al., 2016;). Many of these factors are also risk factors for musculoskeletal pain (Artus et al., 2017; Linton \& Shaw, 2011; Valentin et al., 2016).

Little is known about the characteristics of patients with GTPS who present to physiotherapy services within the National Health Service (NHS). Given the range of risk and prognostic factors associated with GTPS, it is important to understand these characteristics to enable consideration of the applicability of the findings of the LEAP trial to typical NHS patients. Hence the primary aim of this multi-site service evaluation was to collect and synthesise data on the characteristics of patients with a primary complaint of GTPS, presenting to the NHS. As a secondary aim, the characteristics of these NHS patients will then be compared with the participants recruited to the LEAP trial, to provide context of the trial results for an NHS population. 


\section{METHODS}

\section{Recruitment and data analysis}

Four eligible NHS sites from the United Kingdom (UK) responded to a request via Twitter to share anonymised data. The request was aimed at clinicians working within NHS physiotherapy services who had collected data and outcome measures for patients presenting with a primary complaint of GTPS, as part of their routine care over the previous twelve-month period. The request explained the aim of the data collection was to characterise the typical patient who presents to the NHS with GTPS. Examples of the type of information required (age, gender, medical history, duration and distribution of symptoms) was explained in the initial request. Individuals who responded to the request were sent the data capture excel spreadsheet (Appendix 1 ) to enable them to complete local governance approval prior to sharing any data.

The participating sites were made up of two Clinical Musculoskeletal Assessment and Treatment Services (CMATS), one General Hospital and one elective Orthopaedic Hospital. Each site was asked to randomly select approximately 40 patients that had been seen within their service between April 2017 and April 2018, presenting for treatments of lateral hip pain and given a clinical diagnosis of GTPS by the treating physiotherapist in either Consultant led, or physiotherapy out-patient clinics. A clinical diagnosis was accepted for inclusion as clinical testing for GTPS has a high diagnostic validity and physiotherapists in the UK appear confident with a clinical diagnosis for the condition (Ganderton et al., 2017; Stephens et al., 2019). Three sites chose the first forty patients for the given time period who fitted the criteria; whilst one site identified eligible patients at random. The only inclusion criteria applied was a diagnosis of GTPS by the treating clinician, to ensure the sample most accurately reflected the patient who seeks care in the NHS. The domains identified for inclusion in the data capture tool were pre- determined by the lead author (GS) and two co-authors (CL, SON). 
Sites were informed that the anonymised data would be used to define the characteristics of patients with GTPS, attending the NHS.

Medical conditions were classified using the World Health Organisation, International Classification of Diseases 11th Revision (World Health Organisation, 2018) and medications were categorised using the British Medical Association, New guide to Medicine and Drugs, $9^{\text {th }}$ Edition (2015).

Data were analysed descriptively using means, standard deviations and percentages, where relevant. Comparisons of the mean values to the LEAP trial were conducted using t-test for interval and ratio data and chi-squared analysis of categorical data.

\section{Ethical Approval}

Service evaluation, is a process which is used solely to define or judge current care, without reference to a standard (NHS Health Research Authority, 2016). This evaluation defined current care but focussed particularly on the characteristics of patients accessing physiotherapy services. This evaluation collated retrospective data, collected as part of routine clinical practice which had been completely anonymised at site before sharing. It therefore fulfilled criteria of a multi-site service evaluation which did not require NHS Health Research Authority ethical approval. 


\section{RESULTS}

\subsection{Patient characteristics}

Overall, data on 162 subjects was collected and synthesised. The majority of patients were female $(118 / 162 ; 73 \%)$, with an average age of 59 years of age, presenting with unilateral lateral hip pain $(148 / 162 ; 91.4 \%)$ of more than 12 -months in duration $(92 / 162 ; 56.8 \%)$.

BMI data was obtained on $22.2 \%$ of subjects; of those the mean BMI was 28.4; and therefore, classified as 'overweight' (Table 1). 
Table 1. Characteristics and presenting condition.

$\begin{array}{cc}\text { Characteristic } & \begin{array}{c}\text { No. of } \\ \text { subjects } \\ (\% \text { of subjects })\end{array}\end{array}$

Male

Female

Age

BMI

Duration of symptoms

2-6/12

$6-12 / 12$

$>12 / 12$

Pain levels at assessment

VAS (0-10)

Health Related Quality of Life

EQ5D5L Index

MSK-HQ

\section{Problem list}

Walking

Lying / Sleeping

Standing (including sit to stand)

Sitting / driving

Stairs

Exercise / hobbies

Squatting

Bending

Nil reported

Getting in / out of the car

Housework

$106(65.4 \%)$
$98(60.5 \%)$
$79(48.8 \%)$
$39(24.1 \%)$
$22(13.6 \%)$
$14(8.6 \%)$
$10(6.2 \%)$
$7(4.3 \%)$
$4(2.5 \%)$
$2(1.2 \%)$
$1(0.6 \%)$

Mean
(SD)
LEAP No. of subjects

(\% of subjects)

LEAP
Mean

Mean

differences

(SD)

(95\% Cl) p-value

37

(18\%)

167

(82\%)

204

(100\%)

204

28.4

(5.1)

(100\%)

24 (11.8\%)

51 (25\%)

$129(63.2 \%)$

54.8

(8.8)

27.4

(1.0)

4.6

0.0001

$(2.2-6.92)$

1.0

0.012

(0.23-1.77)

0.001

0.14

0.21

$92(56.8)$

114

(70.3\%)

6.5

204

(100\%)

1.6

$<0.0001$

(2.1)

4.9

(1.0)

(1.26-1.94)

71

(43.8\%)

0.6

(0.2)

204

(100\%)

0.7

(0.1)

0.1

$<0.0001$

(0.06-0.14) 36.9 (9.5)

(19.1\%) $\quad 36.9(9.5)$

$\mathrm{X}$

$x$

$\mathrm{x}$

$\mathrm{X}$

$\mathrm{x}$

$\mathrm{X}$

$\mathrm{X}$

$x$

$\mathrm{x}$

$\mathrm{X}$

X 


\subsection{Patient presentations}

All patients presented with a primary complaint of lateral hip pain. Referred symptoms were common, as $30.2 \%$ of patients reported experiencing pain radiating to the lateral thigh (49/162). Associated lower back pain (LBP) was reported by 21.0\% (34/162). Co-existing buttock pain / posterior hip (25/162; 15.4\%); groin / anterior thigh pain (24/162; $14.9 \%)$; ipsilateral knee pain $(14 / 162 ; 8.6 \%)$ and pain below the knee $(12 / 162 ; 7.4 \%)$ were also reported (Fig 1).

\section{Fig 1. Prevalence of referred symptoms of patients with GTPS}

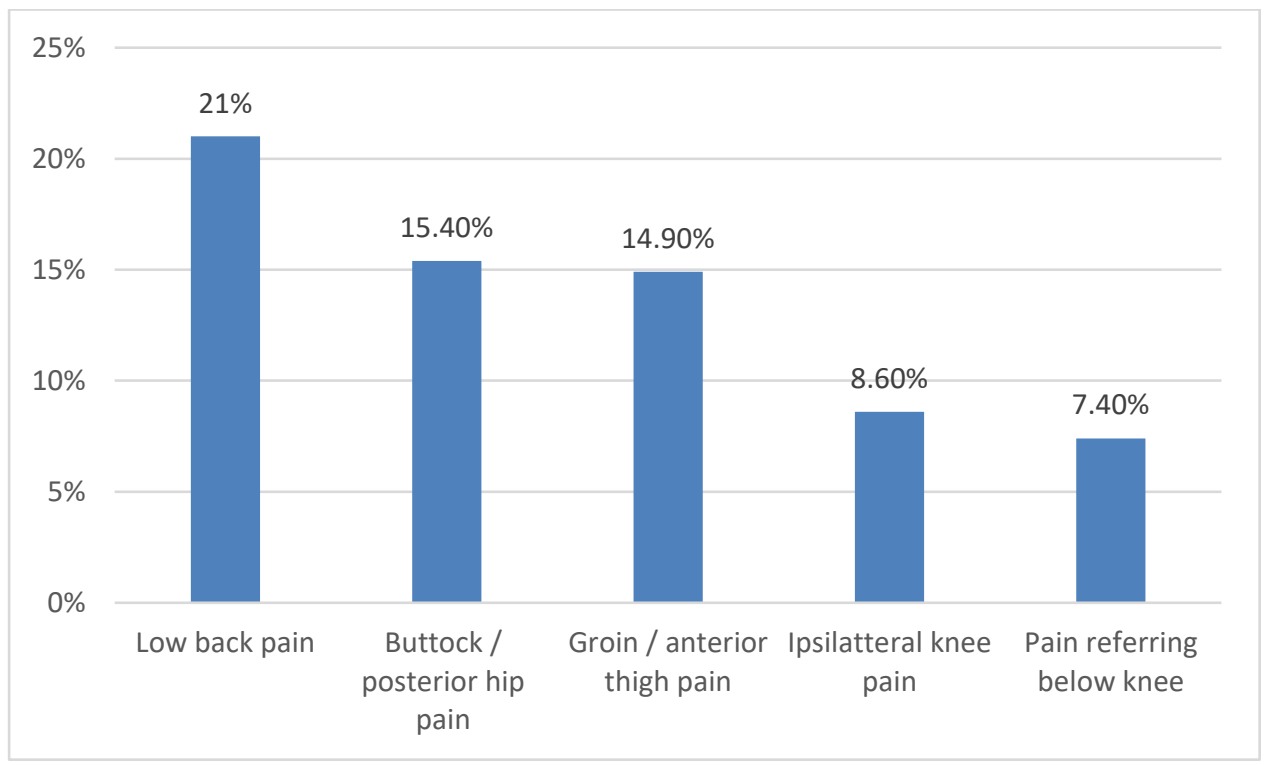

Patients with GTPS commonly reported problems with walking (106/162: 65.4\%), lying / sleeping (98/162; 60.5\%), standing (79/162; 48.8\%) and sitting / driving (39/162; 24.1\%). Subjects reported average pain scores of 6.5 (on a numerical rating scale out of 10) and health related quality of life scores of 0.6 (EQ5D5L). 
Table 2. Medical History of subjects.

$\begin{array}{lrrrr} & \begin{array}{r}\text { No. of } \\ \text { subjects }\end{array} & \begin{array}{r}\% \text { of } \\ \text { subjects }\end{array} & \begin{array}{r}\text { No. of } \\ \text { complaints }\end{array} & \begin{array}{r}\% \text { of total } \\ \text { complaints }\end{array} \\ \text { MSK } & 71 & 43.8 \% & 108 & 30.9 \% \\ \text { Lower limb osteoarthritis } & 25 & 15.4 \% & 29 & 8.3 \% \\ \text { Lower limb arthroplasty } & 19 & 11.7 \% & 29 & 8.3 \% \\ \text { Low back pain } & 19 & 11.7 \% & 19 & 5.4 \% \\ \quad \text { PMR* /Fibromyalgia } & 5 & 3.1 \% & 5 & 1.4 \% \\ \text { Other } & 22 & 13.6 \% & 27 & 7.7 \% \\ \text { Cardiovascular } & 49 & 30.2 \% & 60 & 17.1 \% \\ \text { Digestion } & 31 & 19.1 \% & 34 & 9.7 \% \\ \text { Metabolic/ endocrine } & 29 & 17.9 \% & 32 & 9.1 \% \\ \text { Respiratory } & 20 & 12.3 \% & 21 & 6.0 \% \\ \text { Neoplasms } & 19 & 11.7 \% & 21 & 6.0 \% \\ \text { Nervous system } & 16 & 9.8 \% & 16 & 4.6 \% \\ \text { Mental Health } & 15 & 9.3 \% & 17 & 4.9 \% \\ \text { Gastro-intestinal } & 15 & 9.3 \% & 16 & 4.6 \% \\ \text { Blood } & 5 & 3.1 \% & 5 & 1.4 \% \\ \text { Visual } & 5 & 3.1 \% & 7 & 2.0 \% \\ \text { Ear } & 4 & 2.5 \% & 4 & 1.1 \% \\ \text { Sleep } & 2 & 1.2 \% & 2 & 0.6 \%\end{array}$


One hundred and twenty-eight (79.0\%) subjects reported suffering from 350 health complaints, other than lateral hip pain (Table 2). 56.8\% (92/162) of subjects reported more than one health complaint and within that group, $14.1 \%$ (23/162) had four or more co-existing medical conditions. The most common complaints reported by subjects were musculoskeletal (71/162; 43.8\%), cardiovascular (49/162; 30.2\%), digestion (31/162; 19.1\%) and metabolic / endocrine complaints (29/162; 17.9\%). The 71 subjects, who reported co-existing musculoskeletal problems, reported 108 musculoskeletal complaints. Most commonly lower limb osteoarthritis (25/162; 15.4\%), previous lower limb arthroplasty (19/162; 11.7\%) and low back pain (19/162; 11.7\%). 459 prescribed medications were taken by 134 (82.7\%) subjects; with analgesics being the most commonly prescribed drug (Table 3). Opioid based analgesics (35.2\%), non-opioid based analgesics (34.0\%) and non-steroidal anti-inflammatory analgesics (23.4\%) were the most commonly prescribed medications. The 108 subjects who were taking medication affecting the central nervous system; were taking 150 prescriptions of analgesics. On top of this a further 15 prescriptions of Tri-cyclic antidepressants (such as Amitriptyline), and anti-convulsant medication (such as Gabapentyn) were taken by subjects. These medications are commonly prescribed for the management of persistent pain.

Other than analgesia; medications affecting the cardiovascular system $(54 / 162 ; 34.9 \%)$ and hormone / endocrine system $(30 / 162 ; 18.5 \%)$ were the most commonly prescribed medications. 
Table 3 Medication taken by subjects.

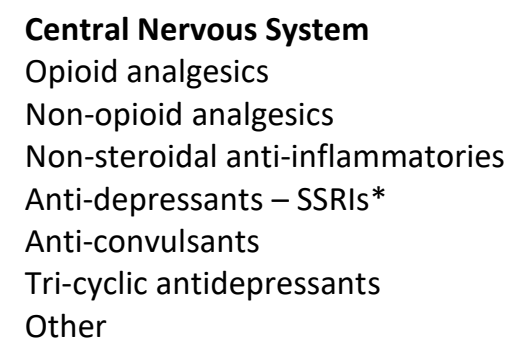

Cardiovascular System

Statins

126

Anti-platelet

Angiotensin 2 blockers

$11.7 \% \quad 19$

Ace inhibitors

$11.1 \%$

Calcium channel blockers

$9.3 \% \quad 15$

Diuretics - Thiazides and loop diuretics

Beta-blockers

$8.0 \%$

Other

Hormone and endocrine system

Diabetes altering medication

Hypo-thyroid medication

Female sex hormones

Other

Gastro-intestinal system

Antacids

Others

Respiratory System

Nutrition

4.3\% 7

Vitamins

Malignant and immune disease Anti-cancer

Reproductive / Urinary System

Others 
The majority of patients $(101 / 162 ; 62.3 \%)$ had undergone radiological investigations for their lateral hip pain as part of this or a previous episode of care, with almost $10 \%(15 / 162 ; 9.3 \%)$ having more than one investigation. X-ray $(71 / 162 ; 44.3 \%)$ was the most commonly performed investigation, followed by MRI scan (32/162; 19.8\%) and ultrasound scan $(11 / 162 ; 6.8 \%)$.

At the point of assessment for the examined episode of treatment, $40.7 \%(66 / 162)$ of subjects had received previous treatment for lateral hip pain, most commonly physiotherapy $(45 / 192 ; 23.4 \%)$ and corticosteroid injection (31/162; 19.1\%). 10.5\% (17/162) of subjects had received more than one type of intervention, and $8.6 \%(14 / 162)$ had received more than one corticosteroid injection.

As part of the examined episode of care, subjects underwent an average of 4.6 (SD 3.0) treatment sessions. The majority of physiotherapists treated subjects with strengthening / loading exercises (149/162; 92.0\%) and education (77/162; 47.5\%); whilst 12.0\% (23/162; 14.2\%) underwent corticosteroid injection.

Clinical outcome data in terms of a numerical rating scale (0-10 or 0-100), was available in $50.6 \%$ $(82 / 162)$ of cases. Patients scoring 0 , were deemed to have had 'no improvement', patients providing the maximum score were deemed to be 'completely resolved' and subjects who provided any scores in between these values, were categorised as having received 'some benefit' from treatment. In two cases $(2 / 82 ; 2.4 \%)$, no numerical rating was provided, instead, it was described that the individual's symptoms had worsened with treatment. The majority demonstrated some improvement $(48 / 82 ; 58.5 \%)$; with similar numbers experiencing no improvement $(15 / 82 ; 18.3 \%)$ as those whose symptoms resolved $(17 / 82 ; 20.7 \%)$. 


\section{DISCUSSION}

The data from this service evaluation suggests that patients presenting to Physiotherapy services within the NHS with a primary complaint of GTPS have different characteristics than participants recruited to the LEAP trial. Comparisons suggest they are older (4.6 years), report higher levels of pain (VAS 1.5), have a higher BMI, and report lower health related quality of life (EQ5D Index 0.1).

Two recent systematic reviews reporting risk factors of persistent, non-malignant pain, suggest that these findings might be important, as people with musculoskeletal conditions who report higher levels of pain and disability at the outset, report poorer clinical outcomes (Artus et al., 2017; Valentin et al., 2016). One of the reviews also reported older age as an important prognostic factor (Valentin et al., 2016). Research looking at other lower limb tendinopathies suggests that the incidence is higher in older age groups, however age is not necessarily a causative factor (Longo et al., 2009; Maffuli \& Kader, 2002). High body mass index (BMI) has not been demonstrated to be a significant prognostic indicator of persistent pain or tendinopathy, however this has not been examined in large cross-sectional studies of patients with GTPS (Artus et al., 2017; Fearon et al., 2012; Lievense et al., 2005; Valentin et al., 2016). Patients with GTPS have been demonstrated to have higher central adiposity than asymptomatic age matches controls; a finding which has been identified as a risk factor for the development of other tendinopathies (Fearon et al., 2012; Gaida, Ashe, Bass \& Cook, 2009; Scott et al., 2015). The typical patient presenting to physiotherapy services in the NHS with GTPS had a higher BMI than the community dwellers recruited to the LEAP trial. Data from this and other studies suggests that the majority of patients with GTPS are 'overweight' according to their BMI (Mellor et al., 2018; Woodley et al., 2008).

This service evaluation suggests that a number of patients presenting to physiotherapy services in the NHS with GTPS experience referral of symptoms into the lateral thigh (30.2\%), lumbar spine (21.0\%), buttock (15.4\%) and groin (14.9\%). This is not a surprise given that so many patients experience pain lasting more than 12 -months $(56.8 \%)$ and the central nervous system adaptions 
which occur with persistent pain (Vardeh et al., 2017). The co-existence of LBP and GTPS is well established, although not well understood or researched, as patients with LBP are often excluded from trials (Tan et al., 2018; Tortolani, Carbone, \& Quartararo, 2012). In this evaluation, $11.7 \%$ of patients suffered persistent LBP and $21.0 \%$, suggested that they experienced back pain alongside their lateral hip pain. In a study of 40 patients seeking healthcare with GTPS; $30 \%$ experienced coexisting low back pain and $75 \%$ had experienced an episode of low back pain in the previous 2 years (Woodley et al, 2008). Patients were excluded from the LEAP trial if they experienced more than 2/10 pain on lumbar spine flexion (Mellor et al., 2016); suggesting that there may be an important group of patients seen in the NHS that were excluded from the LEAP trial.

Nearly half (43.8\%) of the patients with GTPS in this service evaluation were also likely to have other musculoskeletal pain problems, including previous arthroplasty (11.7\%) and lower limb osteoarthritis (15.4\%). Patients with groin pain (>2/10 average intensity over a week) or reduced hip range of motion (<90 degrees flexion) were excluded from the LEAP trial as symptoms from osteoarthritis can often mimic GTPS (Mellor et al., 2016). Our data suggests that groin pain (14.9\%) and osteoarthritis of the lower limb (15.4\%) appear to co-exist with GTPS in a number of cases; a finding supported by other research (Albers, Zwerver, Diercks, Dekker, \& Van Der Akker-Scheek, 2016; Lievense et al., 2005; Segal et al., 2007). This may be significant as Lievense et al, (2005), found that patients with co-existing GTPS and lower limb OA, were almost five times (x4.77) more likely to have symptoms persisting at twelve months. Lower extremity OA appears to co-exist with GTPS in a substantial proportion of patients, and research is required to ascertain how current rehabilitative strategies affect this specific sub-group.

71 subjects in this service evaluation reported 108 different musculoskeletal pain problems. The data in this evaluation on the prevalence of referred symptoms and co-existing musculoskeletal pain problems is significant, as widespread pain has been established a predictor of longer term musculoskeletal pain (Artus et al., 2017; Valentin et al., 2016). Overall, patients attending NHS 
physiotherapy services appear to have co-existing musculoskeletal pain problems. These patients were excluded from the LEAP trial

Seventy-one (43.8\%) patients completed the EQ5D, quality of life questionnaire in this study. On average patients were likely, to have a lower EQ5D index score (0.6), than those in the LEAP trial (0.7). This difference is in line with the suggested minimally important clinical difference (MCID) reported for patients with persistent pain (Corettt \& Ruggeri, in press). What is clear is that these patients experience significantly worse quality of life, than the population norm for adults between the ages of 55-64 in the UK (0.804). This is not the first study to establish that patients with GTPS experience poor quality of life, as Fearon et al (2014), reported that patients with GTPS reported similar quality of life scores, to those with advanced osteoarthritis of the hip. This study supports other data which suggests that lateral hip pain is intrusive, as activities such as walking (65.4\%) and lying (60.5\%) are problematic for the majority of sufferers (Woodley et al, 2008).

The co-morbidities and medication data recorded in this evaluation, suggests that this diminished quality of life may be multi-factorial. 128 subjects suffered 350 medical conditions, including cardiovascular complaints (30.2\%), digestion problems (19.1\%) and metabolic / endocrine disorders (17.9\%) which have all been linked to tendinopathy (Abate et al, 2013). On top of this, 134 subjects were taking 459 prescriptions; and were commonly taking statins (16.7\%) and angiotensin 2 blockers (11.1\%), which have also been linked with the development of tendinopathy and tendon rupture (Kirschgesner et al., 2014; Nyyssonen et al., 2018). It is unknown whether these medications influence rehabilitative outcomes for GTPS.

More than one third of subjects (35.2\%) were taking opioid medication despite current guidelines suggesting these medications should be used judiciously due to side effects and lack of clinical efficacy with their long-term usage (Els et al., 2017; NICE, 2019). 
The burden of managing patients with GTPS for the NHS remains unknown. However, this service evaluation suggests that they frequently suffer high levels of pain and disability and often have symptoms lasting more than 12-months; whilst being on high levels of medication for a range of medical conditions. They also frequently undergo radiological imaging $(62.3 \%)$, despite evidence that clinical examination is sufficient (Fearon et al., 2013; Ganderton, Semciw, Cook \& Pizzari, 2017; Grimaldi et al., 2017) and are treated in a variety of ways including cortico-steroid injections (19.1\%), despite a lack of proven efficacy (Brinks \& Denman, 2011; Rompe et al., 2009). The data in this study importantly suggests that patients presenting to physiotherapy services in the NHS with GTPS are potentially different in clinically important ways than those recruited to the LEAP trial, and have multidimensional needs which may need to be addressed as part of their treatment. Hence, it is unclear whether the findings of the LEAP trial are applicable to patients with GTPS consulting physiotherapy services in the NHS. Further research is warranted to evaluate this.

\section{Limitations}

This service evaluation relied on data from patient records that is dependent on the thoroughness of the documentation of the treating clinician. Methods to select patient records from sites were not standardised which could introduce some selection bias. Also, the diagnosis of GTPS was not standardised, but previously a large survey of current practice suggests that physiotherapists felt confident to diagnose the condition in a reasonably consistent manner (Stephens et al, 2019). 


\section{CONCLUSION}

Patients presenting to the NHS with GTPS appear to have complex, multi-factorial issues with high levels of pain and disability and are often medicated for multiple co-existing conditions. Importantly, they have characteristics which differentiate them from patients recruited to the LEAP trial, Hence, it is unclear whether the findings of the LEAP trial are applicable to patients with GTPS consulting physiotherapy services in the NHS. Further research is warranted to evaluate this. 


\section{Appendix 1. Data capture tool}

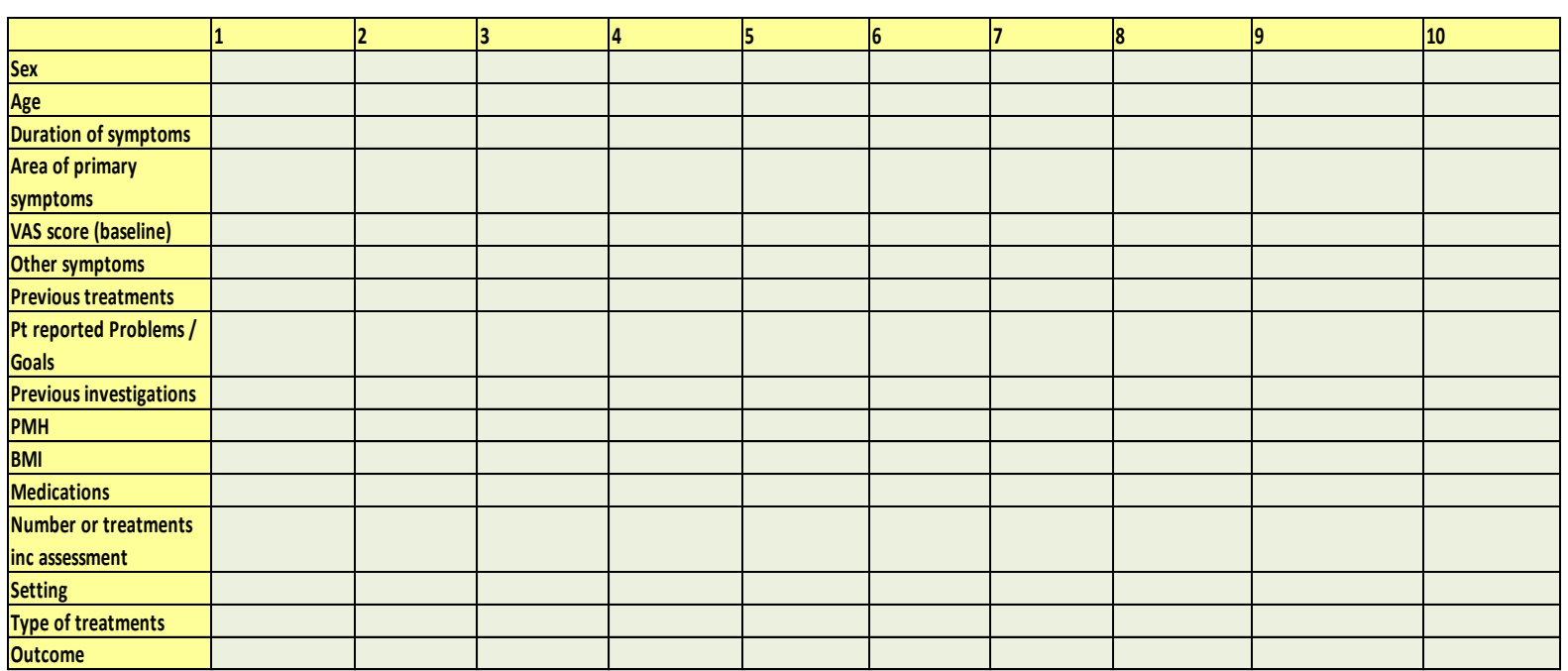




\section{References}

Abate, M., Schiavone, C., Salini, V., \& Andia, I. (2013). Occurrence of tendon pathologies in metabolic disorders. Rheumatology (United Kingdom), 52(4), 599-608.

https://doi.org/10.1093/rheumatology/kes395

Albers, I. S., Zwerver, J., Diercks, R. L., Dekker, J. H., \& Van Den Akker-Scheek, I. (2016). Incidence and prevalence of lower extremity tendinopathy in a Dutch general practice population: A cross sectional study. BMC Musculoskeletal Disorders, 17(1). https://doi.org/10.1186/s12891-016$0885-2$

Artus, M., Campbell, P., Mallen, C. D., Dunn, K. M., \& Van Der Windt, D. A. W. (2017). Generic prognostic factors for musculoskeletal pain in primary care: A systematic review. BMJ Open, 7(1), 1-10. https://doi.org/10.1136/bmjopen-2016-012901

Brinks, A., \& Denman, M. (2011). Corticosteroid injections improved shortterm, but not long-term, recovery and pain in the greater trochanteric pain syndrome. Annals of Internal Medicine. https://doi.org/10.7326/0003-4819-155-8-201110180-02009

British Medical Association new guide to medicine \& drugs (9th ed.). (2015). London: Dorling Kindersley.

Coretti S, Ruggeri M, M. P. (in press). What effect size matters? Comparing methods used for estimation of the 2 Minimum Clinically Important Difference, 1-25. Retrieved from https://editorialexpress.com/cgibin/conference/download.cgi?db_name=SIEP2017\&paper_id $=82$

Cornally, N., \& McCarthy, G. (2011). Chronic Pain: The Help-Seeking Behavior, Attitudes, and Beliefs of Older Adults Living in the Community. Pain Management Nursing, 12(4), 206-217. https://doi.org/10.1016/j.pmn.2010.12.006

Demant, A. W., Kocovic, L., Henschkowski, J., Siebenrock, K. A., Ferrari, P., Steinbach, L. S., \& Anderson, S. E. (2007). Hip pain in renal transplant recipients: Symptomatic gluteus minimus and gluteus medius tendon abnormality as an alternative MRI diagnosis to avascular necrosis. American Journal of Roentgenology, 188(2), 515-519. https://doi.org/10.2214/AJR.05.1097

Els, C., Jackson, T. D., Kunyk, D., Lappi, V. G., Sonnenberg, B., Hagtvedt, R., ... Straube, S. (2017). Adverse events associated with medium- and long-term use of opioids for chronic non-cancer pain: an overview of Cochrane Reviews. The Cochrane Database of Systematic Reviews, 10, CD012509. https://doi.org/10.1002/14651858.CD012509.pub2

Fearon, a. M., Stephens, S., Cook, J. L., Smith, P. N., Cormick, W., \& Scarvell, J. M. (2012). Are child bearing hips a risk factor for Greater trochanteric pain syndrome? Journal of Bodywork and Movement Therapies. https://doi.org/10.1016/j.jbmt.2012.01.060

Fearon, A. M., Cook, J. L., Scarvell, J. M., Neeman, T., Cormick, W., \& Smith, P. N. (2014). Greater trochanteric pain syndrome negatively affects work, physical activity and quality of life: a case control study. The Journal of Arthroplasty, 29(2), 383-386.

https://doi.org/10.1016/j.arth.2012.10.016

Fearon, A. M., Scarvell, J. M., Cook, J. L., \& Smith, P. N. F. (2010). Does ultrasound correlate with surgical or histologic findings in greater trochanteric pain syndrome? A pilot study. Clinical Orthopaedics and Related Research. https://doi.org/10.1007/s11999-009-1174-2 
Fearon, A. M., Scarvell, J. M., Neeman, T., Cook, J. L., Cormick, W., \& Smith, P. N. (2013). Greater trochanteric pain syndrome: defining the clinical syndrome. British Journal of Sports Medicine, 47(10), 649-653. https://doi.org/10.1136/bjsports-2012-091565

Gaida, J. E., Ashe, M. C., Bass, S. L., \& Cook, J. L. (2009). Is Adiposity an Under-Recognized Risk Factor for Tendinopathy ? A Systematic Review, 61(6), 840-849. https://doi.org/10.1002/art.24518

Ganderton, C., Semciw, A., Cook, J., \& Pizzari, T. (2017). Demystifying the Clinical Diagnosis of Greater Trochanteric Pain Syndrome in Women. Journal of Women's Health. https://doi.org/10.1089/jwh.2016.5889

Grimaldi, A., \& Fearon, A. (2015). Gluteal Tendinopathy: Integrating Pathomechanics and Clinical Features in Its Management. Journal of Orthopaedic \& Sports Physical Therapy. https://doi.org/10.2519/jospt.2015.5829

Grimaldi, A., Mellor, R., Nicolson, P., Hodges, P., Bennell, K., \& Vicenzino, B. (2017). Utility of clinical tests to diagnose MRI-confirmed gluteal tendinopathy in patients presenting with lateral hip pain. British Journal of Sports Medicine. https://doi.org/10.1136/bjsports-2016-096175

Kirchgesner, T., Larbi, A., Omoumi, P., Malghem, J., Zamali, N., Manelfe, J., ... Dallaudiere, B. (2014). Drug-induced tendinopathy: from physiology to clinical applications. Joint, Bone, Spine : Revue Du Rhumatisme, 81(6), 485-492. https://doi.org/10.1016/j.jbspin.2014.03.022

Lievense, A., Bierma-Zeinstra, S., Schouten, B., Bohnen, A., Verhaar, J., \& Koes, B. W. (2005). Prognosis of trochanteric pain in primary care. British Journal of General Practice.

Linton, S. J., \& Shaw, W. S. (2011). Impact of Psychological Factors in the Experience of Pain. Physical Therapy, 91(5), 700-711. https://doi.org/10.2522/ptj.20100330

Long, S. S., Surrey, D. E., \& Nazarian, L. N. (2013). Sonography of greater trochanteric pain syndrome and the rarity of primary bursitis. American Journal of Roentgenology. https://doi.org/10.2214/AJR.12.10038

Longo, U. G., Rittweger, J., Garau, G., Radonic, B., Gutwasser, C., Gilliver, S. F., ... Zielin, J. (2009). No Influence of Age, Gender, Weight, Height, and Impact Profile in Achilles Tendinopathy in Masters Track and Field Athletes, 1400-1405. https://doi.org/10.1177/0363546509332250

Maffulli, N., \& Kader, D. (2002). Tendinopathy of tendo achillis. The Journal of Bone and Joint Surgery. British Volume, 84(1), 1-8.

Mellor, R., Bennell, K., Grimaldi, A., Nicolson, P., Kasza, J., Hodges, P., ... Vicenzino, B. (2018). Education plus exercise versus corticosteroid injection use versus a wait and see approach on global outcome and pain from gluteal tendinopathy: prospective, single blinded, randomised clinical trial. The Bmj BMJ, 361. https://doi.org/10.1136/bmj.k1662

Mellor, R., Grimaldi, A., Wajswelner, H., Hodges, P., Abbott, J. H., Bennell, K., \& Vicenzino, B. (2016). Exercise and load modification versus corticosteroid injection versus 'wait and see' for persistent gluteus medius/minimus tendinopathy (the LEAP trial): a protocol for a randomised clinical trial. BMC Musculoskeletal Disorders. https://doi.org/10.1186/s12891-016-1043-6

NHS Health Research Authority . Defining research. London: NHS Health Research Authority (2016), http://www.hra.nhs.uk/documents/2016/06/defining-research.pdf (accessed 18th June 2019).

NICE Guidelines (2019). World Health Organisation. Medicines optimisation in chronic pain, (January 2017), 1-10. 
Nyyssonen, T., Lantto, I., Luthje, P., Selander, T., \& Kroger, H. (2018). Drug treatments associated with Achilles tendon rupture. A case-control study involving 1118 Achilles tendon ruptures. Scandinavian Journal of Medicine \& Science in Sports, 28(12), 2625-2629. https://doi.org/10.1111/sms.13281

Rompe, J. D., Segal, N. A., Cacchio, A., Furia, J. P., Morral, A., \& Maffulli, N. (2009). Home training, local corticosteroid injection, or radial shock wave therapy for greater trochanter pain syndrome. American Journal of Sports Medicine, 37(10), 1981-1990. https://doi.org/10.1177/0363546509334374

Scott, A., Zwerver, J., Grewal, N., de Sa, A., Alktebi, T., Granville, D. J., \& Hart, D. A. (2015). Lipids, adiposity and tendinopathy: is there a mechanistic link? Critical review. British Journal of Sports Medicine, 49(15), 984-988. https://doi.org/10.1136/bjsports-2014-093989

Segal, N. A., Felson, D. T., Torner, J. C., Zhu, Y., Curtis, J. R., Niu, J., \& Nevitt, M. C. (2007). Greater Trochanteric Pain Syndrome: Epidemiology and Associated Factors. Archives of Physical Medicine and Rehabilitation. https://doi.org/10.1016/j.apmr.2007.04.014

Stephens, G., O'Neill, S., French, H. P., Fearon, A., Grimaldi, A., O'Connor, L., ... Littlewood, C. (2019). A survey of physiotherapy practice (2018) in the United Kingdom for patients with greater trochanteric pain syndrome. Musculoskeletal Science and Practice, 40(September 2018), 10-20. https://doi.org/10.1016/j.msksp.2019.01.004

Tan, L. A., Benkli, B., Tuchman, A., Li, X. J., Desai, N. N., Bottiglieri, T. S., ... Lehman, R. A. J. (2018). High prevalence of greater trochanteric pain syndrome among patients presenting to spine clinic for evaluation of degenerative lumbar pathologies. Journal of Clinical Neuroscience : Official Journal of the Neurosurgical Society of Australasia, 53, 89-91. https://doi.org/10.1016/j.jocn.2018.04.030

Thompson, A. E., Anisimowicz, Y., Miedema, B., Hogg, W., Wodchis, W. P., \& Aubrey-Bassler, K. (2016). The influence of gender and other patient characteristics on health care-seeking behaviour: A QUALICOPC study. BMC Family Practice, 17(1), 1-7. https://doi.org/10.1186/s12875-016-0440-0

Tortolani, P. J., Carbone, J. J., \& Quartararo, L. G. (2002). Greater trochanteric pain syndrome in patients referred to orthopedic spine specialists. The Spine Journal : Official Journal of the North American Spine Society, 2(4), 251-254.

Valentin, G. H., Pilegaard, M. S., Vaegter, H. B., Rosendal, M., Ørtenblad, L., Væggemose, U., \& Christensen, R. (2016). Prognostic factors for disability and sick leave in patients with subacute non-malignant pain: a systematic review of cohort studies. BMJ Open, 6(1), e007616. https://doi.org/10.1136/bmjopen-2015-007616

Vardeh, D., Mannion, R. J., Woolf, C. J., Hospital, W., Rd, H., \& Children, B. (2017). Towards a mechanism-based approach to pain diagnosis, 17, 1-36. https://doi.org/10.1016/j.jpain.2016.03.001.

Woodley, S. J., Nicholson, H. D., Livingstone, V., Doyle, T. C., Meikle, G. R., Macintosh, J. E., \& Mercer, S. R. (2008). Lateral Hip Pain: Findings From Magnetic Resonance Imaging and Clinical Examination. Journal of Orthopaedic \& Sports Physical Therapy, 38(6), 313-328. https://doi.org/10.2519/jospt.2008.2685 
World Health Organisation (2018). International Classification of Diseases 11th Revision. Retrieved from https://icd.who.int/en/ (Accessed $18^{\text {th }}$ June 2019) 
